\title{
ASSOCIATION OF VDR GENE VARIANT (rs1544410) WITH TYPE 2 DIABETES IN A PAKISTANI COHORT
}

\author{
Khan $\mathrm{A}^{1}$, Khan $\mathrm{S}^{2}$, Aman $\mathrm{A}^{1}$, Ali $\mathrm{Y}^{1}$, Jamal $\mathrm{M}^{3}$, Rahman B ${ }^{4}, \mathrm{Ahmad} \mathrm{M}^{4}$, Aasim $\mathrm{M}^{4}$, Jalil F ${ }^{1, *}$, Shah AA \\ *Corresponding Author: Dr. Fazal Jalil, Department of Biotechnology, Abdul Wali Khan University \\ Mardan, Toru Road, Near Sheikhmaltoon Twon 23300, Mardan, Khyber-Pakhtunkhwa Province, Pakistan. \\ E-mail: fazaljalil@awkum.edu.pk
}

\begin{abstract}
The present study was designed to measure the mean values of body mass index (BMI), random blood sugar/ fast ing blood sugar (RBS/FBS) tests, and $\mathrm{Hb} \mathrm{A}_{1 \mathrm{c}}$ and to investigate the role of a genetic variant rs 1544410 in the $V D R$ gene in a Pakistani cohort. For this purpose, a total of 917 samples including 469 diabetes mellitus type 2 (T2DM), 145 DM type 1 (T1DM), and 303 healthy control were collected. Out of the total sample set, 500 individuals (250 T2DM cases and 250 controls) were genotyped for rs 1544410 . It was found that $65(26.0 \%)$ cases and 32 (12.8\%) controls had homozygous AA, while 69 (27.6\%) cases and $139(55.6 \%)$ controls had heterozygous $\mathrm{AG}$, and $116(46.4 \%)$ cases and $79(31.6 \%)$ controls had homozygous $\mathrm{GG}\left(\chi^{2}=41.81, p=0.0001\right)$. In addition, a similar distribution of allele frequency was determined in cases and controls $[p$ value $=0.866$; odds ratio $(\mathrm{OR})=0.967$; relative risk $(R R)=1.034]$. A significant difference was observed in homozygous dominant $[\mathrm{OR}=2.394(1.501$ $3.816) ; \mathrm{RR}=1.46(1.225-1.740) ; p=0.003]$ and homozygous recessive models $[\mathrm{OR}=2.970$ (2.086-4.227); RR $=1.798(1.501-2.154) ; p=<0.0001]$ analysis of rs 1544410 in the $V D R$ gene. These findings suggest that the $V D R$ gene is associated with T2DM and genotype GG of ge-

\footnotetext{
$\overline{{ }^{1}}$ Department of Biotechnology, Abdul Wali Khan University Mardan, Mardan, Khyber-Pakhtunkhwa Province, Pakistan

2 Department of Rheumatology, Lady Ready Hospital Peshawar, Peshawar, Khyber-Pakhtunkhwa Province, Pakistan

${ }^{3}$ Deparmetn of Microbiology, Abdul Wali Khan University Mardan, Mardan, Khyber-Pakhtunkhwa Province, Pakistan

${ }^{4}$ Department of Biotechnology, Faculty of Biological Sciences, University of Malakand, Malakand District, Khyber-Pakhtunkhwa Province, Pakistan
}

netic variant rs 1544410 is the susceptible genotype in our Pakistani cohort.

Keywords: Allele frequency; Diabetes mellitus type 2 (T2DM); Polymerase chain reaction (PCR); Single nucleotide polymorphism (SNP).

\section{INTRODUCTION}

Diabetes mellitus type 2 (T2DM) is a multifactorial metabolic disorder, regulated by both genetic and environmental factors [1]. It is a chronic disease that is associated with the incapability of tissues such as liver and skeletal muscles to respond to insulin. Several genetic, as well as environmental factors, contribute to the etiology of T2DM [1]. One of them is vitamin D. Vitamin D deficiency appears to be related to the development of T2DM and metabolic syndrome [2]. Recent studies have shown that high vitamin D status offers protection against T2DM. Vitamin D has important biological functions including modifying insulin secretion and refining insulin resistance [3]. It is a hormone precursor and it has been found to be associated with various metabolic disorders [4]. Its deficiency results in reduced insulin secretion in humans. The frequency of T2DM is exponentially increasing at high rate globally [5]. The survey conducted by the National Diabetes Survey of Pakistan (NDSP 2016-2017) showed that the incidence of diabetes is about $26.3 \%$ in Pakistan [6]. It is already known that vitamin D deficiency is linked with glucose intolerance, insulin resistance, metabolic syndrome, and increases the risk for diabetes [7]. Vitamin $\mathrm{D}$ receptor $(V D R)$ is a steroid family member that acts as a transcriptional activator of several genes [8]. The $V D R$ primarily acts as a transcription factor. The $V D R$ gene on situated on chromosome $12 \mathrm{q} 12-14$. It consists of eight protein-coding exons (exons 2 to 9 ) and six untranslated 
exons that spliced alternatively [9]. It has been investigated that polymorphisms in the VDR gene are associated with diabetes susceptibility. Previous studies have shown the connection of VDR polymorphism with T2DM, however, their frequency remained different across a diverse population [10].

Several techniques are being developed for the identification of single nucleotide polymorphisms (SNPs) but most of them are either expensive or have low sensitivity. Allele-specific polymerase chain reaction (PCR) is one of the less expensive and highly sensitive techniques widely used for the detection for the SNP in several species [11]. The aim of the current study was to detect the association between the rs 1544410 polymorphism of the VDR gene and T2DM in Pakistani patients using allele-specific PCR.

\section{MATERIALS AND METHODS}

Study Subjects. A total of 917 samples, which included 614 diabetes mellitus (DM) patients [469 T2DM and 145 DM type 1 (T1DM)] and 303 control samples' data were collected from different hospitals of the District Swat, Khyber Pakhtunkhwa Province, Pakistan. A questionnaire was designed, and the patients were visited at hospitals to record various information such as random blood sugar/fasting blood sugar (RBS/FBS) tests, body mass index (BMI), age, family history and associated disease of these patients. Study participants were asked to sign a consent form provided in the questionnaire and approval was obtained from the ethics committee of the Department of Biotechnology, Abdul Wali Khan University Mardan, Marden, Khyber Pakhtunkhwa Province, Pakistan. All procedures performed in studies involving human participants were in accordance with the ethics standards of the institutional and/or national research committee and with the 1964 Helsinki declaration and its later amendments or comparable ethics standards. Clinical profiling of the patients was carried out by performing different clinical assessments and diagnostic tests as given below.

Fasting Blood Sugar (FBS) and Random Blood Sugar (RBS) Tests. Blood samples were collected from patients in EDTA-containing vacutainer tubes and processed for RBS and FBS tests. The blood samples were centrifuged for $1 \mathrm{~min}$. at $4000 \mathrm{rpm}$ to extract serum. Then $10 \mu \mathrm{L}$ serum was mixed with $1000 \mathrm{~mL}$ glucose reagents. These test tubes were then left in a water bath for $5 \mathrm{~min}$. After incubation, the mixture was put in the Microlab 330 machine (TLITech Group, Puteaux, France) to record the reading. Individuals with RBS values ranging from 70170 and FBS value ranging from 7-115, were considered normal, while readings higher than 170 for RBS and higher than 115 for FBS, were considered as abnormal and dia- betic. The remaining blood samples were stored at $-20^{\circ} \mathrm{C}$ until needed for further analysis.

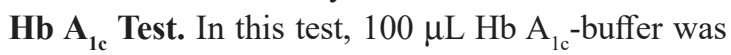
mixed with $5 \mu \mathrm{L}$ blood sample in a test tube. The tubes were placed in a water bath for $12 \mathrm{~min}$. These tubes were placed in the Ichroma ${ }^{\mathrm{TM}}$ machine (BodiTech Med, Inc., Chuncheon-si, Gangwond-do, Korea) to record the reading.

Body Mass Index. The BMI of these patients was calculated from their body weight and height using a universal formula $(\mathrm{BMI}=$ weight/height $)$. The normal BMI value ranges from 19-25. The BMI value higher than this range was considered to be obese.

Glucose Tolerance Test (GTT). The GTT was done by measuring the FBS for each patient after 60, 90 and 120 min. Similarly, the sugar level in the urine of each patient was measured (Table 1).

Genomic DNA Extraction and Primer Designing. Genomic DNA of 250 T2DM patients and 250 control individuals were extraverted using the organic phenolchloroform method. After extraction, DNA was quantified and then stored at $-20{ }^{\circ} \mathrm{C}$ for future experiments. Genomic DNA sequence was retrieved from the National Center for Biotechnology Information (NCBI), and primers for allele-specific PCR were designed using online bioinformatics tools.

Genotyping of the VDR Gene Polymorphism. For genotyping of the VDR gene variant (rs1544410), an allelespecific PCR technique was used for both case and control samples. Two forward primers, each specific to a particular allele (VDR-F1:5'-GCC ACA GAC AGG CCT GCA-3') VDR-F2: 5'-GCC ACA GAC AGG CCT GCG-3') and one common reverse primer (VDR-R: 5'-GTC ACT GCACAT TGC CTC CAA-3') was used for genotyping of $V D R$ in the selected samples. The amplified PCR products were run on a 2.0\% agarose gel and the data was noted for each allele.

\section{RESULTS}

Prevalence of Study Subjects. Clinical and demographic data such as family history, gender, and ages of the patients, associated diseases and $\mathrm{Hb} \mathrm{A}_{1 \mathrm{c}}$ levels of 917 study subjects (459 T2DM, 145 T1DM, 303 controls) were analyzed. The upper and lower ranges of these variables along with the mean/average were calculated at gender level. In male T1DM patients, the mean age was 40 years (5-57), mean BMI was 22.3 (12.7-32.2), mean FBS/RBS was 196.7 (122-384) and $\mathrm{Hb} \mathrm{A}_{1 \mathrm{c}}$ was 9.4 (6.8-15.5). Whereas in female T1DM patients, the mean age was 43.1 years (15-62), mean BMI was 24.6 (16-37.2), RBS/FBS was 219.8 (161-402) and $\mathrm{HbA}_{1 \mathrm{c}}$ was 9.6 (7.3-12.7). In male T2DM patients, the mean age was 57.4 years (32-100), mean BMI was 23.4 (13.5-39.8), mean FBS/RBS was 245 
(135-510) and $\mathrm{Hb} \mathrm{A}_{1 \mathrm{c}}$ mean was 9.6 (6.7-13.7). Similarly, in female T2DM patients, the mean age was 55.4 (29-91), mean BMI was 22.1 (12.3-37.3), mean FBS/RBS was 269.7 (144-510) and $\mathrm{Hb} \mathrm{A} 1 \mathrm{c}$ was 9.8 (6.9-12.7). In the control samples, the mean age was 44 years (10-100), the mean BMI was $21.2(14.5-33.7)$ and the mean FBS/RBS was 112.3 (70-168) (Table 1).

Association of $V D R$ gene with T2DM. A genetic variant (rs1544410) in the $V D R$ gene was mapped in $250 \mathrm{~T} 2 \mathrm{DM}$ patients and 250 controls, as shown in Figures 1 (A) and (B). The frequencies of genotype and allelic distribution and the effect of homozygous dominant and recessive models were determined in cases $v s$. controls. It was found that 65 (26.0\%) cases and $32(12.8 \%)$ controls had homozygous AA, while $69(27.6 \%)$ cases and $139(55.6 \%)$ controls had heterozygous AG, and $116(46.4 \%)$ cases and $79(31.6 \%)$ controls had homozygous GG $\left(\chi^{2}=41.81, p=0.0001\right)$. However, through allele frequency distribution analyses, we determined that 199 (39.8\%) cases and 203 (40.6\%) control individuals had allele A and 301 (60.2\%) cases and 297 (59.4\%) control individuals had allele $\mathrm{G}$ [OR $=0.967$ $(0.751-1.246) ; \mathrm{RR}=0.984(0.866-1.116) ; \mathrm{p}$ value $=0.846]$ (Table 2). The effect of the major allele on the association of $V D R$ with T2DM was checked through homozygous dominant model analysis. Homozygous AA was found in $65(26.0 \%)$ cases and $32(12.8 \%)$ in controls. Similarly,
AG+GG was found $185(74.0 \%)$ and $218(87.20 \%)$ in cases and controls, respectively $(\mathrm{OR}=2.394$ (1.501-3.816); RR $=1.46(1.225-1.740) ; p=0.003)$. Moreover, the effect of the minor allele on the association of $V D R$ with T2DM was assisted through recessive model analysis. Where homozygous GG was observed in $116(46.4 \%)$ cases and 79 (31.28\%) controls and AG+AA was seen in 134 (53.6\%) cases and 271 (68.3\%) controls $(\mathrm{OR}=2.970(2.086-4.227)$; $\mathrm{RR}=1.798$ (1.501-2.154); $p=<0.0001)$ (Table 2).
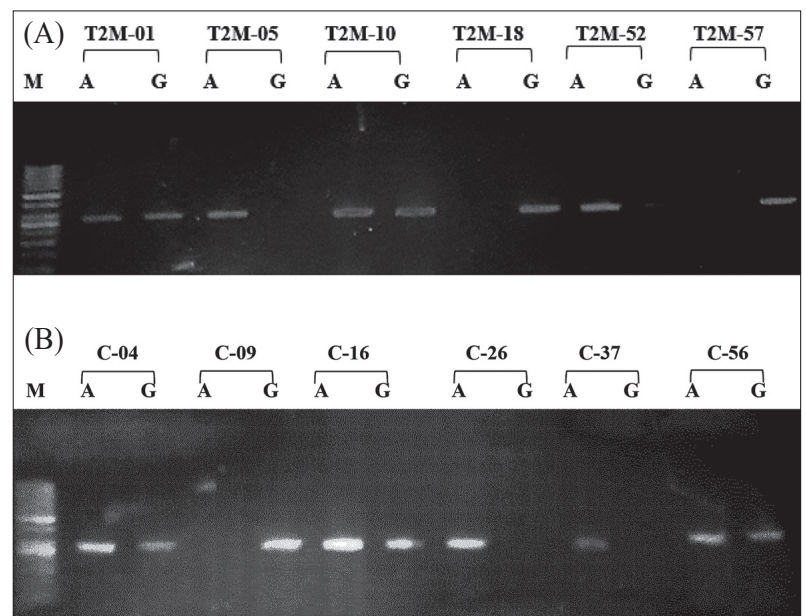

Figure 1. Representative gel pictures depicting genotypes in T2DM cases (A) and controls (B), and controls (C).

Table 1. Upper and lower ranges and mean values of different variables in cases and controls.

\begin{tabular}{|l|l|l|l|l|}
\hline Category & $\begin{array}{l}\text { Age in Years } \\
(\text { mean/range) }\end{array}$ & $\begin{array}{l}\text { BMI }\left(\mathbf{k g} / \mathbf{m}^{2}\right) \\
(\mathbf{m e a n} / \mathbf{r a n g e})\end{array}$ & $\begin{array}{l}\text { RBS/FBS (mg/dL) } \\
(\mathbf{m e a n} / \mathbf{r a n g e})\end{array}$ & $\begin{array}{l}\mathbf{H b}_{\text {1c }}(\mathbf{\%}) \\
(\mathbf{a g e} \text { mean) }\end{array}$ \\
\hline T1DM (males) & $40.0(5-67)$ & $22.3(12.7-32.2)$ & $196.7(122.0-384.0)$ & $9.4(6.8-15.5)$ \\
\hline T1DM (females) & $43.1(15-62)$ & $24.6(16.0-37.2)$ & $219.1(8161.0-402.0)$ & $9.6(7.3-12.1)$ \\
\hline T2DM (males) & $57.4(32.0-100.0)$ & $23.4(13.5-39.8)$ & $245.0(135-510.0)$ & $9.6(6.7-13.7)$ \\
\hline T2DM (females) & $5.5(29.0-91.0)$ & $22.1(12.3-37.3)$ & $? 269.7(144.0-510.0)$ & $9.8(6.9-12.7)$ \\
\hline Controls & $44.0(10.0-100.0)$ & $21.2(14.5-33.7)$ & $112.3(70.0-168.0)$ & - \\
\hline
\end{tabular}

BMI: body mass index; RBS: random blood sugar; FBS: fasting blood sugar.

Table 2. Genotype and allele frequencies $V D R$ gene SNP (rs1544410) using codominant, additive, homozygous dominant, homozygous recessive models.

\begin{tabular}{|c|c|c|c|c|c|c|c|}
\hline Statistical Model & Genotype & $\begin{array}{c}\text { Cases } \\
(n=250)(\%)\end{array}$ & $\begin{array}{c}\text { Controls } \\
(n=250)(\%)\end{array}$ & $\begin{array}{c}\chi^{2} \\
(\mathbf{d f}=2)\end{array}$ & $\begin{array}{c}\text { OR } \\
(95 \% \mathrm{CI})\end{array}$ & $\begin{array}{c}\text { RR } \\
(95 \% \mathrm{CI})\end{array}$ & $p$ Value \\
\hline $\begin{array}{l}\text { Genotype Frequency/ } \\
\text { Codominant Model }\end{array}$ & $\begin{array}{l}\text { AA } \\
\text { AG } \\
\text { GG }\end{array}$ & $\begin{array}{r}65(26.0) \\
69(27.6) \\
116(46.4)\end{array}$ & $\begin{array}{c}32(12.8) \\
139(55.6) \\
79(31.56)\end{array}$ & 41.81 & - & - & 0.0001 \\
\hline $\begin{array}{l}\text { Homozygous Dominant } \\
\text { Model }\end{array}$ & $\begin{array}{l}\mathrm{GG} \\
\mathrm{AG}+\mathrm{AA}\end{array}$ & $\begin{array}{l}116(46.4) \\
134(28.6)\end{array}$ & $\begin{array}{r}79(31.6) \\
271(68.3)\end{array}$ & - & $\begin{array}{l}2.970 \\
(2.086-4.227)\end{array}$ & $\begin{array}{l}1.798 \\
(1.501-2.154)\end{array}$ & $<0.0001$ \\
\hline $\begin{array}{l}\text { Homozygous Recessive } \\
\text { Model }\end{array}$ & $\begin{array}{l}\mathrm{AA} \\
\mathrm{AG}+\mathrm{GG}\end{array}$ & $\begin{array}{c}65(26.0) \\
185(74.0 \%\end{array}$ & $\begin{array}{r}32(12.8) \\
218(87.2)\end{array}$ & - & $\begin{array}{l}2.394 \\
(1501-3.816)\end{array}$ & $\begin{array}{l}1.460 \\
(1.225-1.740)\end{array}$ & 0.003 \\
\hline
\end{tabular}

SNP: single nucleotide polymorphism; OR: odds ratio; $95 \%$ CI: $95 \%$ confidence interval; RR: relative risk. 


\section{DISCUSSION}

It is predicted that there will be an alarming increase in the incidence of diabetes from 382 million (8.3\%) in 2013 to 592 million $(10.1 \%)$ in 2035 . The previous study has shown a strong correlation between the VDR polymorphisms and T2DM-associated metabolic parameters [12]. To briefly explain, the human $V D R$ gene is located on chromosome 12q13.1. The $V D R$ gene consists of coding and non coding exons that is spliced alternatively [13$15]$. Genetic polymorphism in the $V D R$ gene may play an important role in increased $\beta$ cells capacity of secretion, and thus have an association with T1DM and T2DM [16].

In this study, a total of 917 samples, which included 614 DM patients (469 T2DM and 145 T1DM) and 303 control samples' data were collected from different hospitals of District Swat, Khyber Pakhtunkhwa Province, Pakistan. A questionnaire was designed, and the patients were visited at hospitals to record various information such as RBS/FBS, BMI, age, family history and associated disease of these patients. For each variable, the upper and lower ranges and the mean/average was calculated in both males and females. Then a genetic variant rs 1544410 in the $V D R$ gene was genotyped in $250 \mathrm{~T} 2 \mathrm{DM}$ patients and 250 control subjects using the (amplification refractory mutation system) ARMS-PCR method. In the current study, we determined the mean/average values for certain variables in our data stated at the gender level. Our findings are consistent with the observations who studied the association of BMI with T2D in the health records' system in the United States. They recruited 12,179 T2DM and 25,177 healthy controls and concluded that BMI is strongly associated with the risk of being diagnosed with T2DM [17]. In another case-control study, the risks of T2DM focused on the physical activity of individuals. This study was conducted on 279 males and 119 females in Tokyo and was reported that family history of diabetes and smoking are the risk factor for the prevalence of T2DM [18]. Through genotype distribution, we found that $65(26 \%)$ cases had homozygous AA, 69 (27.6\%) cases had heterozygous AG, $116(46.4 \%)$ cases had homozygous GG. Whereas, in control subjects, AA was found in 32 (12.8\%), AG in 139 (55.6\%), GG in 79 (31.6\%). A significant difference was observed at the genotype level in cases and controls $\left(\chi^{2}\right.$ $=41.81, p=0.0001)$. However, through allele frequency distribution analysis, we determined an insignificant difference between T2DM cases and controls ( $p$ value $=0.866$; $\mathrm{OR}=0.967 ; \mathrm{RR}=1.034)$.

The effect of the major allele on the association of the $V D R$ gene with T2DM was checked through homozygous dominant model analysis. Homozygous AA was found in $65(26.0 \%)$ cases and $32(12.8 \%)$ in controls. Simi- larly, $\mathrm{AG}+\mathrm{GG}$ was found in $185(74.0 \%)$ cases and in controls that was $218(87.20 \%)$. Thus, a significant effect of $<0.05$ was observed $(\mathrm{OR}=2.394$ (1.501-3.816); RR $=1.46(1.225-1.740) ; p=0.003)$. Moreover, the effect of the minor allele on the association of the $V D R$ gene with T2DM was assisted through recessive model analysis. Homozygous GG was present in 116 (46.4\%) cases and $79(31.28 \%)$ controls, whereas, $\mathrm{AG}+\mathrm{AA}$ was 134 $(53.6 \%)$ in cases and $271(68.3 \%)$ in controls $(\mathrm{OR}=2.970$ (2.086-4.227); $\mathrm{RR}=1.798$ (1.501-2.154); $p=<0.0001)$. Our data suggest that the VDR gene BsmI (rs1544410) genetic variant is associated with the risk of T2DM in a Pakistani cohort.

To date, more than 25 different polymorphisms have been mapped to the $V D R$ locus. There are several reports that these $V D R$ polymorphisms are associated with T2DM and insulin secretion [19-21]. In addition, $V D R$ polymorphisms are related to metabolic syndrome, metabolic changes related to obesity [22]. The association of the $V D R$ gene polymorphisms and T2DM in older people living in a community of Santiago de Chile, Chile, were previously established through a case-control study on 138 T2DM patients and 172 control subjects with ages ranging from 60-79 years. They further suggested that the $\mathrm{C}$ allele (TC+ CC) of the VDR-FokI gene is a possible risk factor for T2DM in older people living in a community in Santiago de Chile, Chile [10].

In conclusion, the findings of the current study suggest that genotype GG of genetic variant rs 1544410 of the $V D R$ gene is the most susceptible genotype to T2DM, and thus, obesity in patients of the Pakistani cohort. Although, the sample size of our study cohort was small, an extensively large case-control study with a huge sample set is needed to further confirm these findings and to be applied for the management and proper therapeutic intervention by the clinicians.

\section{ACKNOWLEDGMENTS}

The authors gratefully acknowledge the active participation of all patients in the present study.

Declaration of Interest. The authors report no conflicts of interest. The authors alone are responsible for the content and writing of this article.

\section{REFERENCES}

1. Murea M, Ma L, Freedman BI. Genetic and environmental factors associated with type 2 diabetes and diabetic vascular complications. Rev Diabet Stud. 2012; 9(1): 6-22. 
2. Kostoglou-Athanassiou I, Athanassiou P, Gkountouvas A, Kaldrymides P. Vitamin D and glycemic control in diabetes mellitus type 2. Ther Adv Endocrinol Metab. 2013; 4(4): 122-128.

3. Garbossa SG, Folli F. Vitamin D, sub-inflammation and insulin resistance. A window on a potential role for the interaction between bone and glucose metabolism. Rev Endocr Metab Disord. 2017; 18(2): 243-258.

4. Wang H, Chen W, Li D, Yin X, Zhang X, Olsen N, et al. Vitamin D and chronic diseases. Aging Dis. 2017; 8(3): 346-353.

5. Wu Y, Ding Y, Tanaka Y, Zhang W. Risk factors contributing to type 2 diabetes and recent advances in the treatment and prevention. Int J Med Sci. 2014; 11(11): 1185-1200.

6. Basit A, Fawwad A, Qureshi H, Shera AS, Members N. Prevalence of diabetes, pre-diabetes and associated risk factors: Second National Diabetes Survey of Pakistan (NDSP), 2016-2017. BMJ Open. 2018; 8(8): e020961.

7. Hoseini SA, Aminorroaya A, Iraj B, Amini M. The effects of oral vitamin D on insulin resistance in prediabetic patients. J Res Med Sci. 2013: 18(1): 47-51.

8. Pike JW, Meyer MB. The vitamin D receptor: New paradigms for the regulation of gene expression by 1,25-dihydroxyvitamin D3. Rheum Dis Clin North Am. 2012; 38(1): 13-27.

9. Yang L, Wu L, Fan Y, Ma J. Vitamin D receptor gene polymorphisms in association with diabetic nephropathy: A systematic review and meta-analysis. BMC Med Genet. 2017; 18(1): 95.

10. Angel B, Lera L, Marquez C, Albala C. The association of VDR polymorphisms and type 2 diabetes in older people living in community in Santiago de Chile. Nutr Diabetes. 2018; 8(1): 31.

11. Gaudet M, Fara AG, Beritognolo I, Sabatti M. Allelespecific PCR in SNP genotyping. Methods Mol Biol. 2009; 578: 415-424.

12. Zaki M, Kamal S, Basha WA, Youness E, Ezzat W, ElBassyouni $\mathrm{H}$, et al. Association of vitamin D receptor gene polymorphism (VDR) with vitamin D deficiency, metabolic and inflammatory markers in Egyptian obese women. Genes Dis. 2017; 4(3): 176-182.

13. Gyapay G, Schmitt K, Fizames C, Jones H, VegaCzarny N, Spillett D, et al. A radiation hybrid map of the human genome. Hum Mol Genet. 1996; 5(3): 339-346.
14. Pinkel D, Landegent J, Collins C, Fuscoe J, Segraves $\mathrm{R}$, Lucas $\mathrm{J}$, et al. Fluorescence in situ hybridization with human chromosome-specific libraries: Detection of trisomy 21 and translocations of chromosome 4. Proc Natl Acad Sci USA. 1988; 85(23): 9138-9142.

15. Hirai M, Suto Y, Kanoh M. A method for simultaneous detection of fluorescent G-bands and in situ hybridization signals. Cytogenet Cell Genet. 1994; 66(3): 149-151.

16. Mackawy AM, Badawi ME. Association of vitamin $\mathrm{D}$ and vitamin D receptor gene polymorphisms with chronic inflammation, insulin resistance and metabolic syndrome components in type 2 diabetic Egyptian patients. Meta Gene. 2014; 2: 540-556.

17. Ganz ML, Wintfeld N, Li Q, Alas V, Langer J, Hammer M. The association of body mass index with the risk of type 2 diabetes: A case-control study nested in an electronic health records system in the United States. Diabetol Metab Syndr. 2014; 6(1): 50.

18. Tian Z, Li Y, Li L, Liu X, Zhang H, Zhang X, et al. Gender-specific associations of body mass index and waist circumference with type 2 diabetes mellitus in Chinese rural adults: The Henan Rural Cohort Study. J Diabetes Complications, 2018; 32(9): 824-829.

19. Velayoudom-Cephise FL, Larifla L, Donnet JP, Maimaitiming S, Deloumeaux J, Blanchet A, et al. Vitamin D deficiency, vitamin D receptor gene polymorphisms and cardiovascular risk factors in Caribbean patients with type 2 diabetes. Diabetes Metab. 2011; 37 (6): 540-545.

20. Zhang H, Wang J, Yi B, Zhao Y, Liu Y, Zhang K, et al. BsmI polymorphisms in vitamin $\mathrm{D}$ receptor gene are associated with diabetic nephropathy in type 2 diabetes in the Han Chinese population. Gene. 2012; 495(2): 183-188.

21. Ferrarezi DA, Bellili-Munoz N, Dubois-Laforgue D, Cheurfa N, Lamri A, Reis AF, et al. Allelic variations of the vitamin D receptor (VDR) gene are associated with increased risk of coronary artery disease in type 2 diabetics: The DIABHYCAR prospective study. Diabetes Metab. 2013; 39 (3): 263-270.

22. Ruiz-Ojeda FJ, Anguita-Ruiz A, Leis R, Aguilera CM. Genetic factors and molecular mechanisms of vitamin D and obesity relationship. Ann Nutr Metab. 2018; 73(2): 89-99. 
